\title{
Modeling the Dynamics of a Fungal Mycoparasite and Its Host: An Energy-Based Approach
}

\author{
Clemens Stolk, Frank van den Bosch, Aad J. Termorshuizen, and Mike J. Jeger
}

First, third, and fourth authors: Department of Phytopathology, Wageningen Agricultural University, P.O. Box 8025, 6700 EE Wageningen, the Netherlands; second author: Department of Mathematics, Wageningen Agricultural University, Dreijenlaan 4, 6703 HA Wageningen, the Netherlands.

Current address of C. Stolk: Department of Entomology, Wageningen Agricultural University, P.O. Box 8031, 6700 EH Wageningen, the Netherlands.

Accepted for publication 13 February 1998.

Many soilborne plant pathogens pose a threat to agricultural production because they form persistent structures, such as sclerotia $(13,20)$, e.g., Fusarium oxysporum, Rhizoctonia solani, Sclerotinia spp., and Verticillium dahliae. Environmentally safe methods to control these pathogens often do not exist or are insufficiently effective. One approach to developing environmentally safe methods is to select for effective biocontrol agents. One of the mechanisms that may be involved in biological control is direct parasitism on a pathogenic fungus by another fungus (2), usually referred to as mycoparasitism (2, 10,14,24).

An example of a system in which a mycoparasite is able to provide good control is that of the pathogen Sclerotinia minor and the mycoparasite Sporidesmium sclerotivorum $(2,4,17)$. However, experiments with other systems in which mycoparasitism plays an important role do not always show consistent results $(2,34)$. An example of the latter is the combination of the pathogen Verticillium dahliae and the antagonist Talaromyces flavus (M. P. M. Nagtzaam, G. J Bollen, and A. J. Termorshuizen, unpublished data). It is not always clear which factors are responsible for inconsistencies or which factors cause an antagonist to be effective in biological control.

There is a considerable body of empirical data obtained from both laboratory and field experiments on biological control of soilborne pathogens. What has been lacking, however, is a detailed qualitative and quantitative analysis of the processes involved. In a recent paper, Gubbins and Gilligan (21) introduced a model of a parasite-hyperparasite system in the absence of a host, using Lotka-Volterra equations modified to incorporate infected and uninfected parasites. Independently, we have taken as a starting point a different model for analysis of mycoparasitism that concentrates on the energy contents of the host fungus and the mycoparasite. The outcomes of the model are compared to data that apply to the system of Sclerotinia minor and Sporidesmium sclerotivorum $(6,7)$.

The model and model assumptions are introduced, the model results are discussed, and the validity of the assumptions underlying the model, as well as the implications of our findings, are addressed. The type of model developed here, based on general energy concepts, also could be applied to plant-pathogen systems.

Corresponding author: C. Stolk

E-mail address: Clemens.Stolk@medew.ento.wau.nl

Publication no. P-1998-0325-010

(C) 1998 The American Phytopathological Society

\section{THE MODEL}

We model a mycoparasite feeding exclusively on host propagules (e.g., sclerotia). These host propagules are randomly distributed through soil at a certain initial density. They are immobile and do not germinate or multiply. Each host propagule contains a fixed amount of energy. The mycoparasite population initially consists only of propagules (e.g., conidia). The propagules are distributed randomly through the soil. Each propagule contains an energy reserve that enables it to germinate and grow through a certain volume of soil. If a host propagule is encountered, it is consumed, and its energy content is transferred to the mycoparasite, enabling the latter to continue growing.

The system is described by three state variables: $H(t), E_{M}(t)$, and $V(t)$ (Table 1). The variables represent the density of host propagules, the energy content per colony of the mycoparasite, and the volume per colony of the mycoparasite, respectively. It is assumed that a fixed amount of energy is needed for growth of the mycoparasite through a certain volume of soil. The efficiency with which the substrate is converted into growth is assumed to be independent of substrate availability (i.e., the density of host propagules). No explicit assumption concerning the 3-D shape of the mycoparasite colony is made. Maintenance respiration of both the host propagules and the mycoparasite is not considered.

The density of uninfected hosts, $H(t)$, decreases due to infection by the mycoparasite. Over a short time interval, $\Delta t$, this decrease is equal to $H(t+\Delta t)-H(t)$. The host propagules become infected as the total volume of the mycoparasite colonies increases, because over time more host propagules are in the zone colonized by the mycoparasite. In the short time interval from $t$ until $t+\Delta t$, the mycoparasite grows with volume, $V(t+\Delta t)-V(t)$. The total increase in the volume of the mycoparasite over $[t ; t+\Delta t]$ is $M_{0} \cdot[V(t+\Delta t)-V(t)]$. The number of host propagules present in this newly colonized volume equals $M_{0} \cdot[V(t+\Delta t)-V(t)] \cdot H(t)$. Multiplying this with the probability that a host propagule becomes infected if it occurs in the zone colonized by the mycoparasite, $\beta$, equals the number of new infections in the time span $[t ; t+\Delta t]$. Thus, we have the equation

$$
H(t+\Delta t)-H(t)=-M_{0} \beta[V(t+\Delta t)-V(t)] H(t)
$$

Dividing both sides by $\Delta t$ and taking $\lim \Delta t \downarrow 0$ yields

$$
\begin{gathered}
\lim _{\Delta t \downarrow 0} \frac{H(t+\Delta t)-H(t)}{\Delta t}=\lim _{\Delta t \downarrow 0}-M_{0} \beta \frac{V(t+\Delta t)-V(t)}{\Delta t} H(t) \Leftrightarrow \\
d H / d t=-M_{0} \beta V^{\prime}(t) H(t)
\end{gathered}
$$

with $V^{\prime}(t)=d V / d t$. The initial host density at $t=0$ is $H_{0}$. Therefore, $H(0)=H_{0}$. 
Let us consider the energy content per mycoparasite colony. The change in energy content per mycoparasite over a short time interval, $\Delta t$, equals $E_{M}(t+\Delta t)-E_{M}(t)$. The energy content of a mycoparasite colony decreases as energy is used for growth and increases as it encounters host propagules that are being parasitized. The growth of the mycoparasite in terms of volume during $[t ; t+\Delta t]$ equals $V(t+\Delta t)-V(t)$. Per unit of volume growth, the amount of energy that is needed is $\gamma$. Therefore, the decrease in energy content per mycoparasite during this short time interval equals $\gamma \cdot[V(t+\Delta t)-V(t)]$. As can be seen from the derivation of equation 1 , the number of host propagules that then becomes infected per mycoparasite equals $\beta \cdot[V(t+\Delta t)-V(t)] \cdot H(t)$. Because every host propagule contains $\varepsilon_{H}$ of energy, the increase in energy content per mycoparasite colony equals $\varepsilon_{H} \beta \cdot[V(t+\Delta t)-$ $V(t)] \cdot H(t)$. Combining energy drain and energy gain into one equation yields

$$
E_{M}(t+\Delta t)-E(t)=-\gamma[V(t+\Delta t)-V(t)]+\varepsilon_{H} \beta[V(t+\Delta t)-V(t)] H(\mathrm{t})
$$

Dividing both sides by $\Delta t$ and taking $\lim \Delta t \downarrow 0$ yields

$$
\begin{gathered}
\lim _{\Delta t \downarrow 0} \frac{E_{M}(t+\Delta t)-E_{M}(t)}{\Delta t}=\lim _{\Delta t \downarrow 0}\left[-\gamma \frac{V(t+\Delta t)-V(t)}{\Delta t}+\varepsilon_{H} \beta \frac{V(t+\Delta t)-V(t)}{\Delta t} H(t)\right] \Leftrightarrow \\
d E_{M} / d t=-\gamma V^{\prime}(t)+\varepsilon_{H} \beta V^{\prime}(t) H(t)
\end{gathered}
$$

At time $t=0$, a mycoparasite consists only of a propagule. Therefore, its energy content is identical to that of a propagule of the mycoparasite: $E_{M}(0)=\varepsilon_{M}$.

The density of infected propagules of the host at time $t$ can be calculated from

$$
I(t)=H_{0}-H(t)
$$

\begin{tabular}{|c|c|c|}
\hline Symbol & Definition & Dimension \\
\hline \multicolumn{3}{|c|}{ Model variables } \\
\hline$H(t)$ & $\begin{array}{l}\text { Density of uninfected propagules of the host } \\
\text { at time } t\end{array}$ & $N_{H} L^{-3}$ \\
\hline$I(t)$ & $\begin{array}{l}\text { Density of infected propagules of the host at } \\
\text { time } t\end{array}$ & $N_{I} L^{-3}$ \\
\hline$V(t)$ & $\begin{array}{l}\text { Total volume per mycoparasite colony at } \\
\text { time } t\end{array}$ & $L^{3} N_{M}^{-1}$ \\
\hline$V^{\prime}(t)$ & Growth rate of the mycoparasite & $L^{3} N_{M}^{-1} T^{-1}$ \\
\hline$E_{M}(t)$ & Energy content per mycoparasite at time $t$ & $E N_{M}^{-1}$ \\
\hline \multicolumn{3}{|c|}{ Model parameters } \\
\hline$H_{0}$ & $\begin{array}{l}\text { Density of uninfected propagules of the host } \\
\text { at time } t=0\end{array}$ & $N_{H} L^{-3}$ \\
\hline$M_{0}$ & $\begin{array}{l}\text { Density of propagules of the mycoparasite at } \\
\text { time } t=0\end{array}$ & $N_{M} L^{-3}$ \\
\hline$\varepsilon_{M}$ & $\begin{array}{l}\text { Energy content per mycoparasite at time } t= \\
0 \text { (i.e., the amount of energy present in a } \\
\text { propagule of the mycoparasite) }\end{array}$ & $E N_{M}^{-1}$ \\
\hline$\varepsilon_{H}$ & Energy content per particle of the host & $E N_{H}^{-1}$ \\
\hline$\beta$ & $\begin{array}{l}\text { Probability that a particle of the host be- } \\
\text { comes infected if it occurs in zone } V(t)\end{array}$ & \\
\hline$\gamma$ & $\begin{array}{l}\text { The amount of energy needed for one unit of } \\
\text { volume growth of the mycoparasite }\end{array}$ & $E L^{-3}$ \\
\hline$\theta$ & $\begin{array}{l}\text { The specific rate at which the energy reserve } \\
\text { of the mycoparasite is converted into } \\
\text { growth rate, } V_{M}^{\prime}(t)\end{array}$ & $L^{3} E^{-1} T^{-1}$ \\
\hline \multicolumn{3}{|c|}{ Model output quantities } \\
\hline$F$ & $\begin{array}{l}\text { Fraction of propagules of the host that be- } \\
\text { come infected for } t \rightarrow \infty\end{array}$ & $\cdots$ \\
\hline$V_{\max }$ & $\begin{array}{l}\text { The maximum volume that a mycoparasite } \\
\text { colony can attain }\end{array}$ & $L^{3} N_{M}^{-1}$ \\
\hline
\end{tabular}

In equations 2 and 4 , the derivative $V^{\prime}(t)$ appears on the right side of the equations. $V^{\prime}(t)$ is the growth rate of the mycoparasite. A

TABLE 1. Notations used in the model ${ }^{\mathrm{a}}$

a Dimensions are $N_{H}=$ number of uninfected propagules of the host; $N_{I}=$ number of infected propagules of the host; $\mathrm{N}_{M}=$ number of propagules of the mycoparasite; $L=$ unit of length; $E=$ unit of energy; and $T=$ unit of time. $E$ is defined as $M L^{2} T^{-2}$, where $M=$ unit of mass. number of features of the model appear to be independent of the definition of $V^{\prime}(t)$.

\section{GROWTH RATE-INDEPENDENT CHARACTERISTICS}

Using the separation of variables method (11), equation 2 can be solved:

$$
H(t)=H_{0} e^{-M_{0} \beta V(t)}
$$

Substituting this solution in differential equation 4 and using the variation of parameters method (11) we find the solution:

$$
E_{M}(t)=-\gamma V(t)+\varepsilon_{H} H_{0} \beta \int_{0}^{t} V^{\prime}(\sigma) e^{-M_{0} \beta V(\sigma)} d \sigma+\varepsilon_{M}
$$

From this solution of the model, various properties can be derived. We first derive an expression for the proportion of hosts infected over a long period of time $(t \rightarrow \infty)$, and then, two threshold criteria for growth of the mycoparasite are derived.

The mycoparasite stops growing when its energy reserve is depleted, i.e., when $E_{M}(t)=0$. When this is true for $t \rightarrow \infty$, the volume of soil colonized by the mycoparasite is at its maximum, $V_{\max }$. This value is independent of the growth rate $V^{\prime}(t)$ and can be derived from the following equation, which is obtained by filling in $E_{M}(t)=0$ and $t \rightarrow \infty$ from equation 7 :

$$
0=-\gamma V_{\max }+\varepsilon_{H} H_{0} \beta \int_{0}^{\infty} V^{\prime}(\sigma) e^{-M_{0} \beta V(\sigma)} d \sigma+\varepsilon_{M}
$$

The integral in equation 8 can be simplified, because the integrand is the derivative of $\left(-1 / M_{0} \beta\right) e^{-M_{0} \beta V(t)}$. We find

$$
-\gamma V_{\max }+\varepsilon_{H}\left(H_{0} / M_{0}\right) \cdot\left(1-e^{-M_{0} \beta V_{\max }}\right)+\varepsilon_{M}=0
$$

Based on equations 5 and 6 , it follows that the density of infected propagules of the host, $I(t)$, is

$$
I(t)=H_{0}\left(1-e^{-M_{0} \beta V(t)}\right)
$$

If $I_{\max }$ is defined as the density of infected host propagules at the time the mycoparasite stops growing, the fraction, $F$, of host propagules ultimately infected is

$$
F=I_{\max } / H_{0}=1-e^{-M_{0} \beta V_{\max }}
$$

$V_{\max }$, on the right side of equation 11 , cannot explicitly be solved from equation 9. However, for given values of all other parameters in equation $9, V_{\max }$ can be determined numerically by Newton iteration (15). Once $V_{\max }$ is known, $F$ can be determined from equation 11. In Figures 1 and 2, $V_{\max }$ and $F$ are given as functions of $M_{0}, H_{0}, \gamma, \varepsilon_{M}$, and $\varepsilon_{H}$. Parameter values used in these graphs are of a realistic order of magnitude for a biological system. The probability, $\beta$, that a host propagule becomes infected once it is in a zone colonized by the mycoparasite has been set at 1 . The values of the energy contents of the mycoparasite and host propagules (joules per propagule) are similar to those found by Adams et al. (6). As for $\gamma$, to our knowledge no explicit measurements have ever been conducted on the amount of energy it takes for a fungus to grow through a particular amount of soil. However, we assumed a minimum value for $\gamma$ of $\approx 10^{-5} \mathrm{~J} \mathrm{~mm}^{-3}$ (details are provided in the appendix).

Growth of the mycoparasite will occur as long as its energy reserves are not depleted. The energy content of a mycoparasite will increase as long as $d E_{M} / d t>0$. Using equation 4 , this yields

$$
\varepsilon_{H} \beta H(t)>\gamma
$$

This criterion can be explained as follows. Growth of the mycoparasite over one unit of volume requires $\gamma$ units of energy. This quantity is at the right side of the equation. In this volume, $H(t)$ host propagules are encountered, of which a fraction, $\beta$, is actually parasitized. Because each host propagule contains $\varepsilon_{H}$ of energy, the left side of the equation represents the energy gained by a 
mycoparasite growing over 1 unit of volume. Thus, equation 12 states that the amount of energy gained by growth over a certain volume should be greater than the amount of energy lost as a result of this growth, if an increase in the energy reserve is to occur.

Let us consider the case of $H(t)=H_{0}$. Based on equation 12, it follows that expansive growth of the mycoparasite initially only occurs if

$$
H_{0}>\frac{\gamma}{\varepsilon_{H} \beta}
$$

At initial densities of the host lower than this value, the mycoparasite will not be able to establish itself successfully. Equation 13, therefore, is a threshold criterion for mycoparasite establishment.

\section{EPIDEMIC CURVES}

The results discussed so far are independent of the growth rate, $V^{\prime}(t)$, of the mycoparasite. To obtain epidemic curves, which are solutions to equations 6 and 7, however, the growth rate, $V^{\prime}(t)$, should be specified. In the following calculations, we assume the growth rate depends linearly on the energy content of the mycoparasite:

$$
V^{\prime}(t)=\theta E_{M}(t)
$$

Because no explicit solutions to equations 6 and 7 exist, numerical approximations were obtained by Euler's method of numerical integration (15). Graphs of these solutions are shown in Figure 3.
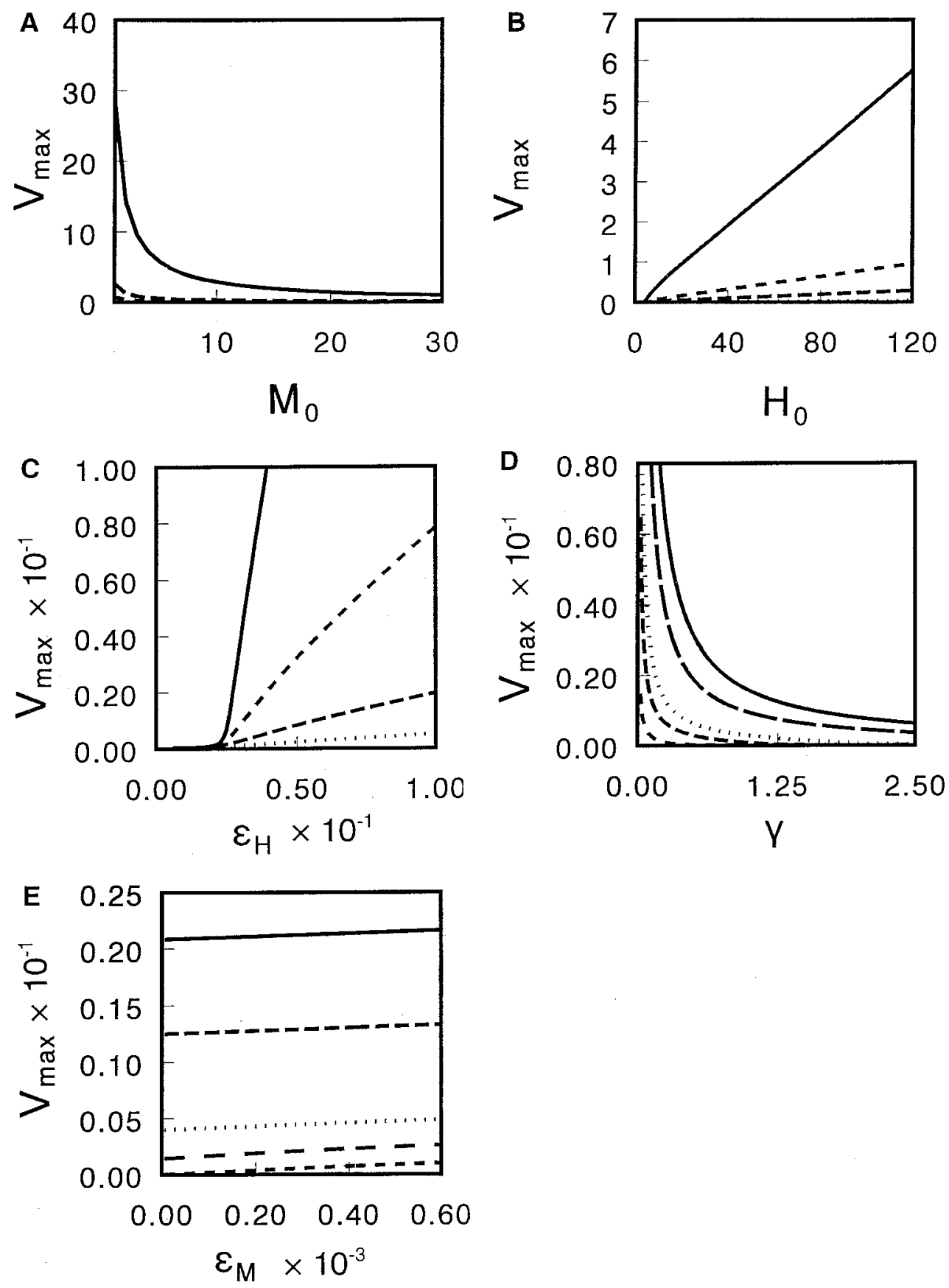

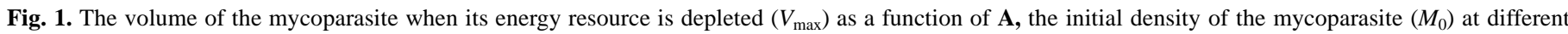
initial densities of the host $\left(H_{0}\right)$ (from top to bottom, $H_{0}=120,12,6$, and 3); $\mathbf{B}$, the initial density of the host $\left(H_{0}\right)$ at different initial densities of the mycoparasite $\left(M_{0}\right)$ (from top to bottom, $M_{0}=5,30,100$, and 800); $\mathbf{C}$, the energy content of the propagules of the host $\left(\varepsilon_{H}\right)$ at different values of $M_{0}$ (from top to bottom, $M_{0}=10,50,200$, and 800$)$; $\mathbf{D}$, the amount of energy needed per unit of volume growth of the mycoparasite $(\gamma)$ at different values of the energy content of the propagules of the host $\left(\varepsilon_{H}\right)$ (from top to bottom, $\varepsilon_{H}=0.5,0.3,0.1,510^{-2}, 110^{-2}$, and $510^{-3}$ ); and $\mathbf{E}$, the energy content of the propagules of the mycoparasite $\left(\varepsilon_{M}\right)$ at different values of $\varepsilon_{H}$ (from top to bottom, $\varepsilon_{H}=0.5,0.3,0.1,510^{-2}, 110^{-2}$, and $510^{-3}$ ). Values of the other parameters are $\beta=1.0 ; H_{0}=25 ; M_{0}=800$; and $\gamma=0.75$. 
Now that solutions to equations 6 and 7 are known, it is possible to study the time it takes for a mycoparasite to infect $50 \%$ of the host propagules: the halving time $\left(t_{h}\right)$. The halving time is a measure of the effectiveness of a mycoparasite. Figure 4 shows the halving time as a function of $H_{0}$ and $M_{0}$, respectively.

\section{EXPERIMENTAL DATA}

The model was fitted to experimental data of the Sclerotinia minor-Sporidesmium sclerotivorum system. We used data from Adams et al. (6,7). The cosmopolitan Sclerotinia minor is among the most polyphagous of plant pathogens $(3,37)$. In lettuce, Sclerotinia minor causes lettuce drop. The infection results in rotting of the bottom of the plant, followed by wilting of the plant. Fi- nally, sclerotia are formed, which allow the fungus to survive for long periods of time under unfavorable conditions. Sclerotia of Sclerotinia minor probably can survive for 3 to 5 years $(1,3)$.

Sporidesmium sclerotivorum is an ecologically obligate parasite of sclerotia of Sclerotinia species $(8,17)$, as well as others. Sporidesmium sclerotivorum has been isolated from soils in Australia, East Asia, Europe, and North America (2,5). It produces macroconidia, microconidia, chlamydospores, and microsclerotia $(2,17)$. The multicellular macroconidia germinate in the presence of host sclerotia (9). When encountering a host sclerotium, Sporidesmium sclerotivorum germ tubes penetrate between cells of the rind and cortex, followed by formation of haustoria-like infection structures $(12,17)$. Field experiments have shown that
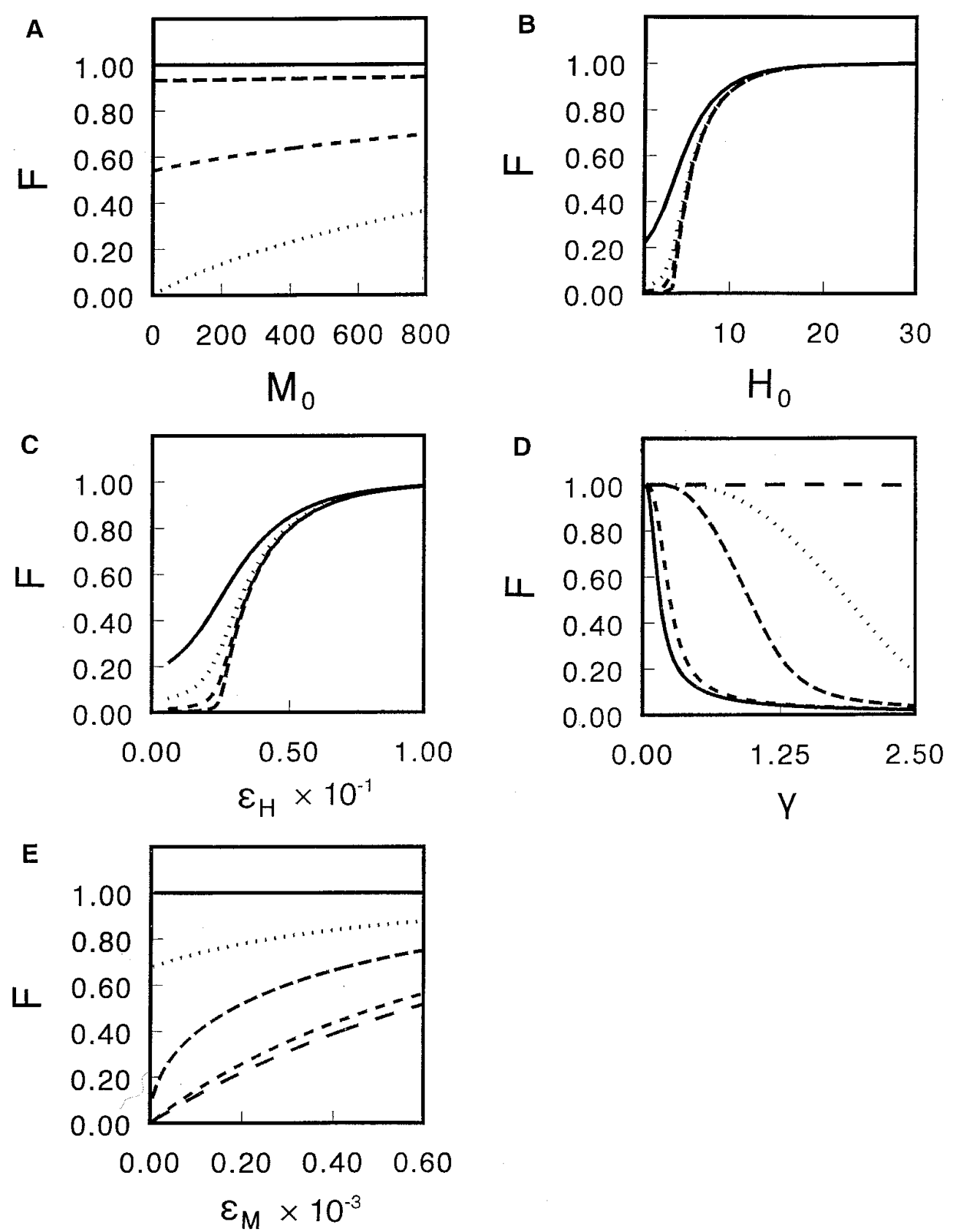

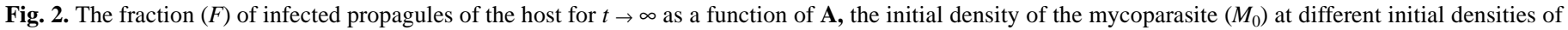

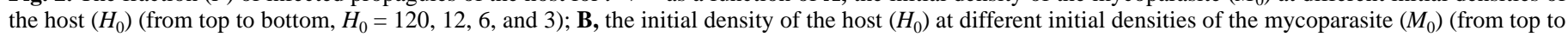

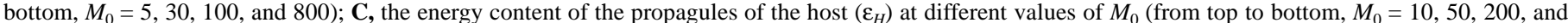

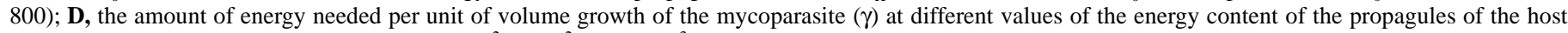

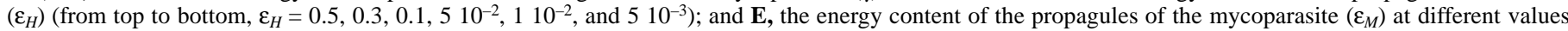
of $\varepsilon_{H}$ (from top to bottom, $\varepsilon_{H}=0.5,510^{-2}, 310^{-2}, 110^{-2}$, and $510^{-3}$ ). Values of the other parameters are $\beta=1.0 ; H_{0}=25 ; M_{0}=800 ;$ and $\gamma=0.75$. 
Sporidesmium sclerotivorum is a good candidate for commercial biological control of lettuce drop in the field $(2,4,17)$.

Adams et al. (7) studied the effect of Sporidesmium sclerotivorum on sclerotia of Sclerotinia minor. They reported that the proportion of inactivation of Sclerotinia minor was related to the density of macroconidia of Sporidesmium sclerotivorum. Adams et al. (6) also determined the energy contents of Sclerotinia minor sclerotia and Sporidesmium sclerotivorum macroconidia (Table 2).

The model was fitted to these data to obtain estimates of model parameters. Klepper and Rouse (25) described a means of finding model parameters that results in a model output that best fits the real system output. The algorithm they described was incorporated into a computer program, and this program was used to fit the model to the experimental data described by Adams et al. (7). The weight-related quantities (macroconidia per gram of soil and sclerotia per $100 \mathrm{~g}$ of soil) were transformed into volume-related quantities by the specific weight of sand $\left(1.6 \mathrm{~g} \mathrm{~mm}^{-3}\right.$ of sand $)$. The values of $M_{0}$ (initial density of macroconidia of Sporidesmium sclerotivorum) were set at the values given by Adams et al. (7). The values of $H_{0}$ (initial density of sclerotia of Sclerotinia minor), $\beta, \gamma, \theta, \varepsilon_{H}$, and $\varepsilon_{M}$ were estimated by the program. The resulting best set of parameter values are $H_{0}\left(N_{H} \mathrm{~mm}^{-3}\right)=8.2110^{-3} ; \beta=$ 0.644; $\varepsilon_{H}\left(\mathrm{~J} \mathrm{~N}_{H}^{-1}\right)=0.299 ; \varepsilon_{M}\left(\mathrm{~J} \mathrm{~N}_{M}{ }^{-1}\right)=5.5610^{-5} ; \gamma\left(\mathrm{J} \mathrm{mm}^{-3}\right)=$ $3.1510^{-5}$; and $\theta\left(\mathrm{mm}^{3} \mathrm{~J}^{-1}\right.$ day $\left.^{-1}\right)=74.6$ (dimensions are described in Table 1). The model output is shown together with the experimental data in Figure 5.

\section{DISCUSSION}

The model described in this paper uses the concept of flows of energy to explain microorganismal dynamics. The concept of energy has been utilized in biology only in few cases (e.g., Koojman [27], van Haren et al. [40], and Zoneveld and Kooijman [41]). Several researchers have mentioned the term "energy" in relation to phytopathological issues. For instance, Garrett (19) defined inoculum potential as "the energy of growth of a fungal parasite available for infection of a host at the surface of the host organ to be infected." In this definition, energy can be divided into endogenous and exogenous energy $(28,29)$. For soilborne plant pathogens with low competitive saprotrophic ability, the exogenous

\section{A}

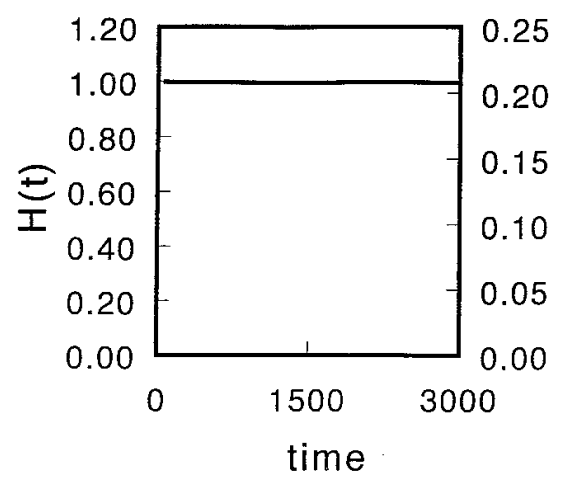

C

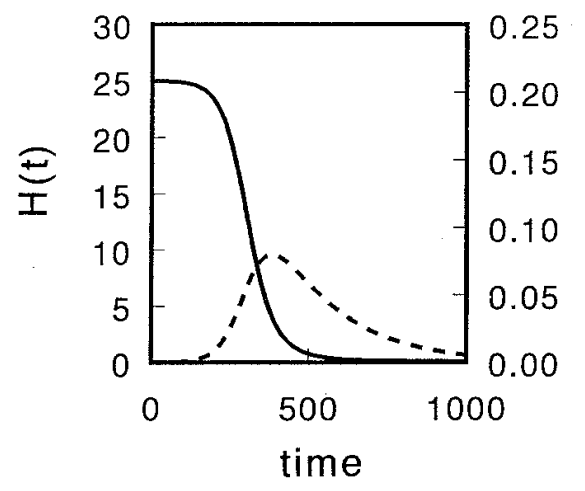

E

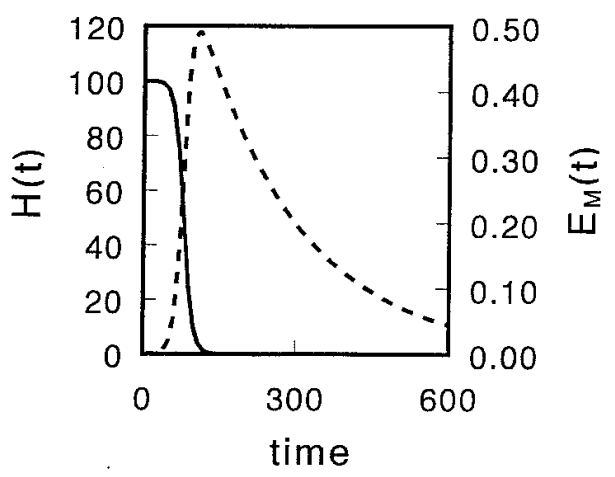

B

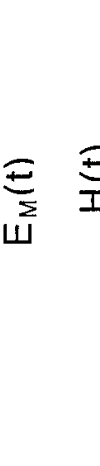

D

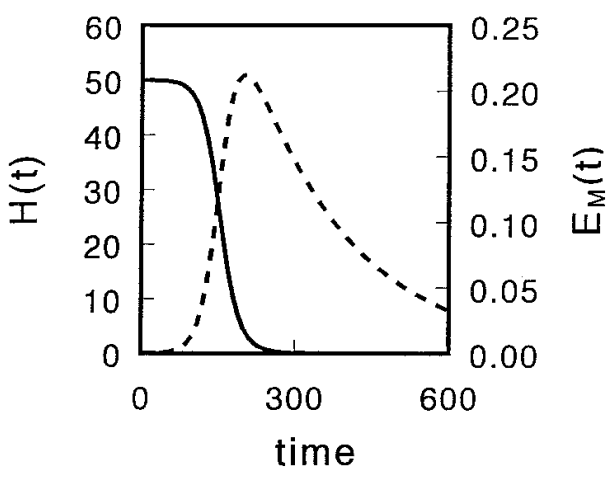

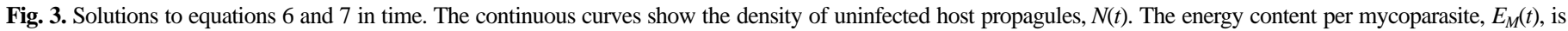
represented by the dashed curves. Parameter values are $M_{0}=10 ; \beta=1.0 ; \varepsilon_{H}=610^{-2} ; \varepsilon_{M}=610^{-5} ;$ and $\gamma=0.25$. The $H_{0}$ values are $\mathbf{A}, 1 ; \mathbf{B}, 10 ; \mathbf{C}, 25 ; \mathbf{D}, 50 ;$ and $\mathbf{E}, 100$. 
energy component of inoculum potential is mainly provided by root exudates. The endogenous energy component refers to the energy available in the infectious propagule itself. Lockwood (31) emphasized that competition for nutrients among soilborne fungi is primarily competition for energy. He also discussed important phenomena, such as soil fungistasis, lysis of fungal hyphae, and formation of persistent structures, as characteristic responses to energy stress in soil $(30,31)$.

The analytical results of the model provide some insight into the system of a mycoparasite and its host. Based on equation 11, it appears that the fraction of host propagules that finally become infected does not depend on the growth trajectory of the mycoparasite over time, i.e., the final result is independent of assumptions concerning the growth rate of the mycoparasite.

The criterion for expansive growth of the mycoparasite (equation 12) does not contain the parameters $M_{0}$ and $\varepsilon_{M}$, whereas it does contain $H(t)$ and $\varepsilon_{H}$. In other words, the initial inoculum density of the mycoparasite and the energy content of its propagules do not affect its probability of establishment. This largely agrees with the findings of Adams et al. (7). They found complete destruction of sclerotia of Sclerotinia minor by Sporidesmium sclerotivorum after 14 weeks, regardless of whether they applied the mycoparasite at a density of 5 or 5,000 macroconidia per $g$ of soil. Only at 0.5 macroconidia per $g$ of soil was the mycoparasite unable to establish itself. If the term inoculum potential were applied to this particular host-mycoparasite system, it would indicate that the endogenous energy component is of limited importance in terms of successful mycoparasitism.
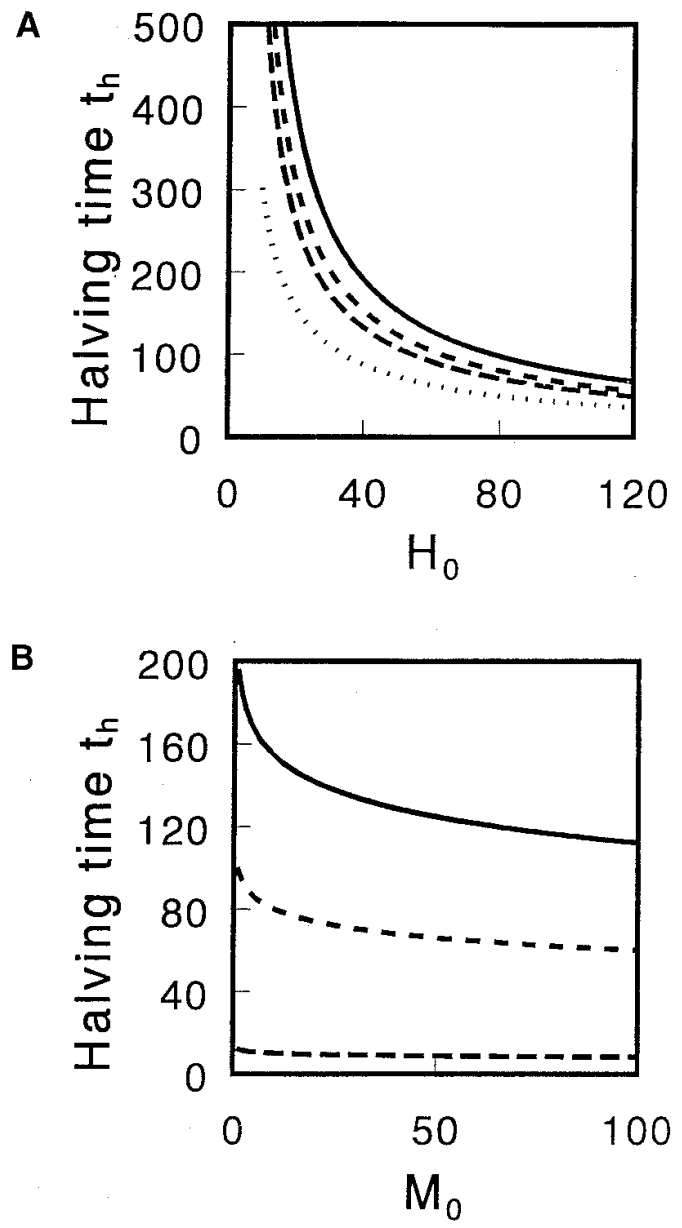

Fig. 4. The halving time, $t_{h}$, as a function of $\mathbf{A}$, the initial density of the host, $H_{0}$ (from top to bottom, the values of $M_{0}$ are $10,50,120$, and 800 ); and $\mathbf{B}$, the initial density of the mycoparasite, $M_{0}$ (from top to bottom, the values of $N_{0}$ are 50,100 , and 1,000). Values of the other parameters are $\beta=1.0 ; \varepsilon_{H}=610^{-2}$; $\varepsilon_{M}=610^{-5} ; \gamma=0.25 ;$ and $\theta=210^{-2}$.
Figure 2A and B also shows that above a certain value of initial host density, changing the initial density of the mycoparasite, $M_{0}$, does not have any effect on the fraction of the host propagules that ultimately become infected. In other words, at sufficiently high densities of the host, the initial density of the mycoparasite is not important in determining the state of control that is finally achieved.

Fravel et al. (18) showed that the increase in suppression of Sclerotinia minor is less with increasing inoculum levels of Sporidesmium sclerotivorum. This result is apparent in Figure 2A. Especially at the lowest density of the host (represented by the lowest curve), increasing densities of the mycoparasite result in diminishing returns in terms of the fraction of infected host propagules (Fig. 2A).

A good fit of the model with experimental data was obtained. Parameter values all agreed with the expectations, except $\varepsilon_{H}$ (the energy content of a host sclerotium) and $\gamma$ (the energy required for 1 unit of volume growth of the mycoparasite). $\varepsilon_{H}$ was overestimated by approximately five times. One reason for this may be that Adams et al. (7) mixed the soil they had amended with sclerotia and macroconidia every 2 weeks. It is likely that this positively affected the spread of the mycoparasite through the soil in their experiment. A higher $\varepsilon_{H}$, as estimated by the program, logically is linked to a higher rate of mycoparasite dispersion. The estimated value of $\gamma$ was somewhat below the value we assumed to be its lower limit. However, Adams et al. (6) showed that Sporidesmium sclerotivorum is very efficient in converting substrate into mycelium compared to other fungi. Germination of macroconidia of Sporidesmium sclerotivorum is triggered by the presence of host sclerotia $(32,33)$. This could be interpreted as host-directed growth, which is not accounted for in the model. Host-directed growth can be regarded as an energy-saving mechanism. Therefore, the estimated value of $\gamma$ still might be realistic.

This simple model certainly falls short in several aspects. The sclerotia and macroconidia are assumed to be distributed randomly through the soil. Although this was the case in the experiment used for validation (7), in the field the sclerotia of Sclerotinia minor and macroconidia of Sporidesmium sclerotivorum usually have a clustered distribution $(2,3)$. In a recent model study, Gubbins and Gilligan (22) showed that heterogeneous mixing of the pathogen and mycoparasite in this system enhanced persistence of the mycoparasite.

The host sclerotia also are assumed to be inactive, i.e., immobile and not reproducing, germinating, or respiring. On a short time scale, these processes may be ignored, especially if a fallow field situation is considered. On a longer time scale, however, they can be of great importance. The same is true for the mycoparasite. However, in situations in which inundative biological control is to be practiced, the mycoparasite generally will be applied to the soil before planting.

Germination of macroconidia of Sporidesmium sclerotivorum is reported to depend on the density of available host sclerotia, the distance to the host sclerotia, and the time that macroconidia are incubated together with host sclerotia $(3,32,33)$. These may be important factors and are not included in the model.

The model assumes the mycoparasite grows with a fixed amount of energy needed for a certain volume of growth. This is reflected

TABLE 2. Energy content of Sclerotinia minor sclerotia and Sporidesmium sclerotivorum macroconidia, as reported by Adams et al. (6) ${ }^{\mathrm{a}}$

\begin{tabular}{llcc}
\hline Structure & $\begin{array}{c}\text { Relative energy } \\
\text { content }\left(\mathrm{J} \mathrm{g}^{-1}\right)\end{array}$ & $\begin{array}{c}\text { Average } \\
\text { weight }(\mathrm{g})\end{array}$ & $\begin{array}{c}\text { Energy } \\
\text { content } \\
(\mathrm{J} / \text { propagule })\end{array}$ \\
\hline $\begin{array}{l}\text { Sclerotinia minor } \\
\text { sclerotium }\end{array}$ & $16,487 \pm 1,159$ & $3.5310^{-6}$ & $5.8210^{-2}$ \\
$\begin{array}{l}\text { Sporidesmium sclerotivorum } \\
\text { macroconidium }\end{array}$ & 16,336 & $4.710^{-9}$ & $7.6810^{-5}$ \\
\hline
\end{tabular}

a Numbers in the third column are calculated from the data in the other two columns. 
in parameter $\gamma$. However, it could be that the efficiency with which sclerotia are consumed depends on their density. Such an effect is not accounted for in the model.

The growth rate of the mycoparasite is assumed to be linearly dependent on its energy content. However, the relationship between energy content and growth rate may be of a different kind. For instance, in the fungal growth model of Paustian and Schnürer $(35,36)$, the growth rate also is linearly dependent on substrate availability, but there is a minimum amount of substrate below which the growth rate is 0 . There also may be a maximum growth rate above which extra substrate is not translated into any increase in growth rate (comparable to the Holling functional response in animal predator-prey systems) (23). Indeed, Gubbins and Gilligan (21) applied the theory of functional and numeric responses to their model of the Sclerotinia sclerotiorum-Sporidesmium sclerotivorum system. They (21) found that the simplest type of functional response (a constant multiplied by the density of sus- ceptible host sclerotia) was appropriate for an adequate description of the data.

If the differential equations describing changes in $H(t)$ and $E_{M}(t)$ over time are multiplied by $\varepsilon_{H}$ and $M_{0}$, respectively, these differential quantities can be expressed in identical dimensions, namely energy per unit of volume $\left(E L^{-3}\right) . V(t)$ then can be redefined by multiplication with $\gamma$ and $M_{0}$. $V^{*}(t)$ also has the dimension $E L^{-3}$. This yields the following set of equations:

$$
\left\{\begin{array}{l}
d H^{*} / d t=-(\beta / \gamma) V^{* \prime}(t) H^{*}(t) \\
d E_{M}{ }^{*} d t=-V^{*}(t)+(\beta / \gamma) V^{*}(t) H^{*}(t) \\
d V^{* / d}=\theta \gamma E_{M} *(t)
\end{array}\right.
$$

where $V^{* \prime}(t)=d V^{*} / d t$. These equations describe the populations of host and mycoparasite in terms of the "energy density" present in the populations. The two equations for the mycoparasite (describing $d E_{M} * / d t$ and $d V^{*} / d t$ ) represent the amount of energy that
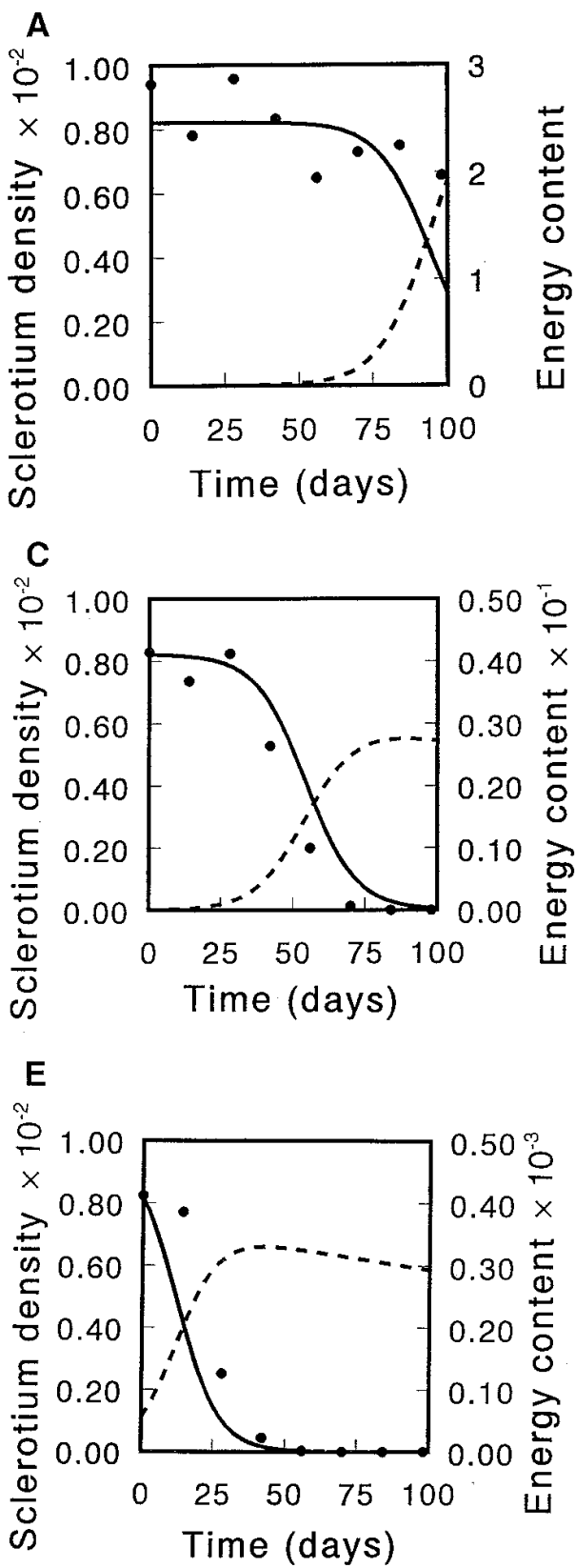

B

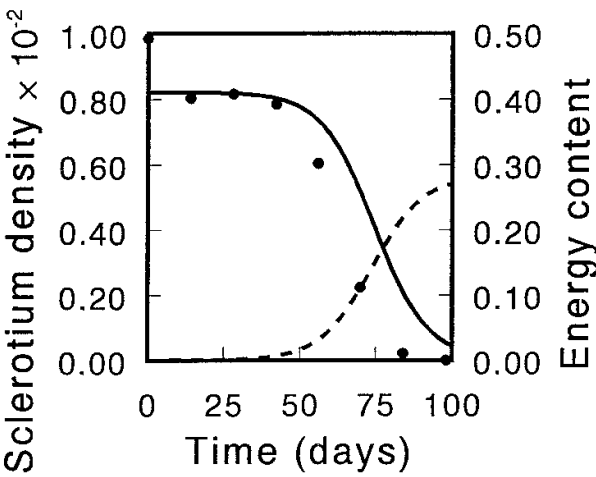

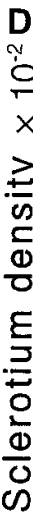

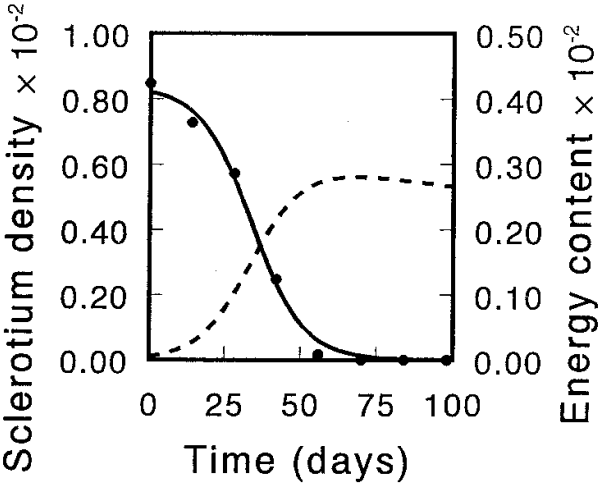

Fig. 5. Comparison of model data with experimental data. The continuous lines and black circles represent the simulated and observed sclerotial densities, respectively. The dashed curves represent the energy content per mycoparasite predicted by the model. The parameter values used are $H_{0}=8.2110^{-3}$ sclerotia per $\mathrm{mm}^{3}, \varepsilon_{H}=2.9910^{-1} \mathrm{~J}$ per sclerotium, $\varepsilon_{M}=5.5610^{-5} \mathrm{~J}$ per macroconidium, $\gamma=3.1510^{-5} \mathrm{~J} \mathrm{~mm}^{-3}, \theta=74.6 \mathrm{~mm}^{3} \mathrm{~J}^{-1} \mathrm{day}^{-1}$, and $\beta=0.64$. The initial densities of the mycoparasite (macroconidia per cubic millimeter) are $\mathbf{A}, 810^{-4} ; \mathbf{B}, 810^{-3} ; \mathbf{C}, 810^{-2} ; \mathbf{D}, 810^{-1} ;$ and $\mathbf{E}, 8.0$. 
is still available for growth and the amount of energy that has already been invested in growth, respectively. This investment is irreversible. This new set of equations has the advantage that all quantities can be compared because they have equal dimensions.

The type of modeling approach used here also could be applied to other pathogen-mycoparasite systems, as well as to plant-pathogen interactions and tritrophic plant-pathogen-mycoparasite interactions. For instance, it has been suggested that certain fungal antagonists use weakened or dead tissue of potato roots as a nutritional base from which they attack Rhizoctonia solani, a pathogen of potato $(16,38,39)$. An energy-based model could be used to investigate the relative importance of such alternative energy sources for a biocontrol agent.

Two of the model parameters are defined strictly in terms of energy. $\gamma$, the amount of energy needed for 1 unit of volume growth of the mycoparasite, has dimensions of stress or pressure (the dimensions would be $\left[M L^{2} T^{-2}\right] L^{-3}=M L^{-1} T^{-2}=$ joules per cubic meter or Pascal). The inverse of $\theta$, the growth rate per quantity of energy reserve of the mycoparasite, has dimensions of viscosity $\left(L^{-3}\left[M L^{2} T^{-2}\right] T=M L^{-1} T^{-2}=\right.$ kilograms per meter per second). Do these physical dimensions assist in the biological interpretation of inoculum potential? We can see that $\gamma$ represents the stress or pressure that the mycoparasite must overcome to grow. The value of $\theta$ indicates the ease with which the mycoparasite can grow through soil: at high values, there is low viscosity, and the converse is true. However, a better link to inoculum potential may be provided by the variables defined in the set of equations presented in equation $15 . V^{*}(t)$ represents the energy of the mycoparasite already invested in growth per unit of volume of soil; $E_{M} *(t)$ is the energy of the mycoparasite still available for investment in growth per unit of volume of soil. Both of these variables have well-defined physical dimensions of stress or pressure (三 potential, as in matric potential). It appears that $E_{M} *(t)$ bears the closest relationship to the concept of inoculum potential, although it does not in itself specify the mycoparasite to be at the surface of the host propagule to be infected (as required in Garrett's definition). However, it may not be possible, or even necessary, to obtain a completely congruent physical definition. This is the first attempt to provide a physical justification for the concept. We propose the term "growth potential" to describe the energy of a fungal pathogen or parasite available for investment in growth per unit of volume of soil.

\section{APPENDIX}

The value of $\gamma$ depends on many factors, such as the density of the mycelium, the thickness of individual hyphae, the energy content of the hyphae, and the intensity of the growth respiration. It is likely that none of the factors that make up $\gamma$ are constant. Knudsen and Bin (26) reported a hyphal density of 10 to $70 \mathrm{~mm} \mathrm{~mm}^{-3}$ of soil for Trichoderma harzianum. The energy content of mycelium of Sporidesmium sclerotivorum is $18,387 \pm 381 \mathrm{~J} \mathrm{~g}^{-1}$ dry weight (6). If we assume a hyphal weight of $3.4610^{-9} \mathrm{~g} \mathrm{~mm}^{-1}$ and $10 \%$ dry weight, a $10 \mathrm{~mm}$ length of hyphae per $\mathrm{mm}^{3}$ of soil represents $6.410^{-5} \mathrm{~J} \mathrm{~mm}^{-3}$ of energy. However, if we assume a higher hyphal density, thicker hyphae, and a nonzero growth respiration, $\gamma$ may be several orders of magnitude higher. Lockwood (31) stated that most of the energy available to soil microflora is required for maintenance. Therefore, even a value of $\gamma=0.25$, as is used in Figures 1 and 2, may be realistic.

\section{ACKNOWLEDGMENTS}

We thank two anonymous reviewers for their comments on an earlier draft.

\section{LITERATURE CITED}

1. Abawi, G. S., and Grogan, R. G. 1979. Epidemiology of diseases caused by Sclerotinia species. Phytopathology 69:899-904.

2. Adams, P. B. 1990. The potential of mycoparasites for biological control of plant diseases. Annu. Rev. Phytopathol. 28:59-72.

3. Adams, P. B., and Ayers, W. A. 1979. Ecology of Sclerotinia species. Phytopathology 69:869-899.

4. Adams, P. B., and Ayers, W. A. 1982. Biological control of Sclerotinia lettuce drop in the field by Sporidesmium sclerotivorum. Phytopathology 72:485-488.

5. Adams, P. B., and Ayers, W. A. 1984. The world distribution of the mycoparasites Sporidesmium sclerotivorum, Teratosperma oligocladum and Laterispora brevirama. Soil Biol. Biochem. 17:583-584.

6. Adams, P. B., Ayers, W. A., and Marois, J. J. 1985. Energy efficiency of the mycoparasite Sporidesmium sclerotivorum in vitro and in soil. Soil Biol. Biochem. 17:155-158.

7. Adams, P. B., Marois, J. J., and Ayers, W. A. 1984. Population dynamics of the mycoparasite, Sporidesmium sclerotivorum, and its host, Sclerotinia minor, in soil. Soil Biol. Biochem. 16:627-633.

8. Ayers, W. A., and Adams, P. B. 1979. Mycoparasitism of sclerotia of Sclerotinia and Sclerotium species by Sporidesmium sclerotivorum. Can. J. Microbiol. 25:17-23.

9. Ayers, W. A., and Adams, P. B. 1979. Factors affecting germination, mycoparasitism, and survival of Sporidesmium sclerotivorum. Can. J. Microbiol. 25:1021-1026.

10. Baker, R. 1987. Mycoparasitism: Ecology and physiology. Can. J. Plant Pathol. 9:370-379.

11. Boyce, W. E., and DiParma, R. C. 1977. Elementary Differential Equations. John Wiley \& Sons, New York.

12. Bullock, S., Adams, P. B., Willetts, H. J., and Ayers, W. A. 1986. Production of haustoria by Sporidesmium sclerotivorum in sclerotia of Sclerotinia minor. Phytopathology 76:101-103.

13. Coley-Smith, J. R., and Cooke, R. C. 1971. Survival and germination of fungal sclerotia. Annu. Rev. Phytopathol. 9:65-92.

14. Deacon, J. W., and Berry, L. A. 1992. Modes of action of mycoparasites in relation to biocontrol of soilborne plant pathogens. Pages 157-167 in: Biological Control of Plant Diseases. E. C. Tjamos, G. C. Papavizas, and R. J. Cook, eds. Plenum Press, New York.

15. Doucet, P., and Sloep, P. B. 1992. Mathematical Modeling in the Life Sciences. Ellis Horwood, New York.

16. Fahima, T., and Henis, Y. 1990. Interactions between pathogen, host and biocontrol agent: Multiplication of Trichoderma hamatum and Talaromyces flavus on roots of diseased and healthy hosts. Pages 165-180 in: Biological Control of Soil-borne Pathogens. D. Hornby, ed. CAB International, Wallingford, England, U.K.

17. Fravel, D. R. 1997. Use of Sporidesmium sclerotivorum for biocontrol of sclerotial plant pathogens. Pages 37-47 in: Plant-Microbe Interactions and Biological Control. G. J. Boland and L. D. Kuykendall, eds. Marcel Dekker, Inc., New York.

18. Fravel, D. R., Adams, P. B., and Potts, W. E. 1992. Use of disease progress curves to study the effects of the biocontrol agent Sporidesmium sclerotivorum on lettuce drop. Biocontrol Sci. Technol. 2:341-348.

19. Garrett, S. D. 1956. Biology of Root-Infecting Fungi. Cambridge University Press, Cambridge.

20. Ghaffer, A. 1988. Biological control of sclerotial diseases. Pages 153 175 in: Biocontrol of Plant Diseases, vol. 1. K. G. Mukerji and K. L. Garg, eds. CRC Press, Inc., Boca Raton, FL.

21. Gubbins, S., and Gilligan, C. A. 1996. Population dynamics of a parasite and a hyperparasite in a closed system: Model analysis and parameter estimation. Proc. R. Soc. Lond. B 263:1071-1078.

22. Gubbins, S., and Gilligan, C. 1997. A test of heterogeneous mixing as a mechanism for ecological persistence in a disturbed environment. Proc. R. Soc. Lond. B 264:227-232.

23. Holling, C. S. 1966. The functional response of invertebrate predators to prey density. Mem. Entomol. Soc. Can. 48:1-86.

24. Jeffries, P., and Young, T. W. K. 1994. Interfungal Parasitic Relationships. CAB International, Wallingford, England, U.K.

25. Klepper, O., and Rouse, D. I. 1991. A procedure to reduce parameter uncertainty for complex models by comparison with real system output illustrated on a potato growth model. Agric. Syst. 36:375-395.

26. Knudsen, G. R., and Bin, L. 1990. Effects of temperature, soil moisture, and wheat bran on growth of Trichoderma harzianum from alginate pellets. Phytopathology 80:724-727.

27. Kooijman, S. A. L. M. 1993. Dynamic Energy Budgets in Biological Systems. Cambridge University Press, Cambridge.

28. Lockwood, J. L. 1986. Soilborne plant pathogens: Concepts and connections. Phytopathology 76:20-27.

29. Lockwood, J. L. 1988. Evolution of concepts associated with soilborne 
plant pathogens. Annu. Rev. Phytopathol. 26:93-121.

30. Lockwood, J. L. 1990. Relation of energy stress to behaviour of soilborne plant pathogens and to disease development. Pages 197-214 in: Biological Control of Soil-borne Pathogens. D. Hornby, ed. CAB International, Wallingford, England, U.K.

31. Lockwood, J. L. 1992. Exploitation competition. Pages 243-263 in: The Fungal Community: Its Organization and Role in the Ecosystem. G. C. Carroll and D. T. Wicklow, eds. Marcel Dekker, Inc., New York.

32. Mischke, S., and Adams, P. B. 1996. Temporal and spatial factors affecting germination of macroconidia of Sporidesmium sclerotivorum. Мycologia 88:271-277.

33. Mischke, S., Mischke, C. F., and Adams, P. B. 1995. A rind-associated factor from sclerotia of Sclerotinia minor stimulates germination of a mycoparasite. Mycol. Res. 99:1063-1070.

34. Papavizas, G. C., and Lumsden, R. D. 1980. Biological control of soilborne fungal propagules. Annu. Rev. Phytopathol. 18:389-413.

35. Paustian, K., and Schnürer, J. 1987. Fungal growth response to carbon and nitrogen limitation: A theoretical model. Soil Biol. Biochem. 19:613620.

36. Paustian, K., and Schnürer, J. 1987. Fungal growth response to carbon and nitrogen limitation: Application of a model to laboratory and field data. Soil Biol. Biochem. 19:621-629.

37. Purdy, L. H. 1979. Sclerotinia sclerotiorum: History, diseases and symptomatology, host range, geographic distribution, and impact. Phytopathology 69:875-880.

38. Van den Boogert, P. H. J. F., Jager, G., and Velvis, H. 1990. Verticillium biguttatum: An important mycoparasite for the control of Rhizoctonia solani in potato. Pages 77-91 in: Biological Control of Soil-borne Pathogens. D. Hornby, ed. CAB International, Wallingford, England, U.K.

39. Van den Boogert, P. H. J. F., and Velvis, H. 1992. Population dynamics of the mycoparasite Verticillium biguttatum and its host, Rhizoctonia solani. Soil Biol. Biochem. 24:157-164.

40. Van Haren, R. J. F., Hendrikx, E. M. L., and Atkinson, H. J. 1994. Growth curve analysis of sedentary plant parasitic nematodes in relation to plant resistance and tolerance. Pages 172-184 in: Predictability and Nonlinear Modelling in Natural Sciences and Economics. J. Grasman and G. van Straten, eds. Kluwer Academic Publishers, Dordrecht, the Netherlands.

41. Zonneveld, C., and Kooijman, S. A. L. M. 1989. The application of a dynamic energy budget model to Lynmaea stagnalis. Funct. Ecol. 3:269278. 